\title{
Eccrine Porocarcinoma: A Rare Entity and Review of the Literature
}

\author{
Elharrouni Alaoui Aicha*, Douhi Zakia, Elloudi Sara, Baybay Hanane, and Mernissi Fz \\ Department of Dermatology, CHU Hassan II FEZ, Morocco
}

\begin{abstract}
Eccrine porocarcinoma is an extremely rare malignancy of the eccrine sweat gland. It can either arise de novo or it can develop in a long standing eccrine poroma. It often occurs in the elderly, with the mean age of occurrence being 67 years. The tumour favours extremities, particularly the legs and feet. Dermoscopy is an invaluable technique in diagnosing skin tumors. Keeping in view its rarity of occurrence, we are here by presenting a case of eccrine porocarcinoma and especially dermoscopic characteristics which occurred in a 55 year old male in unusual location.
\end{abstract}

Keywords: Eccrine porocarcinoma; Sweat gland tumour; Malignant; Dermoscopy; Metastases

\section{Introduction}

Eccrine porocarcinoma (EPC) is a rare malignant skin tumor presumably arising from the intraepidermal ductal portion of the sweat gland, usually arises in elderly patients, frequently in the extremities [1]. Due to its non-specific clinical appearance of a pink dome-shaped nodule with occasional ulceration, EPC must be differentiated from other various kinds of skin tumors. Dermoscopy is a noninvasive technique that has been shown to increase significantly the clinical diagnosis of cutaneous tumors. However, few cases of EPC have been reported using dermoscopic images, and the clinical details were not well examined [2]. We report a case of eccrine porocarcinoma and especially dermoscopic characteristics in unusual localization.

\section{Case Report}

A 57-year-old lady presented with pigmented, plaque-like lesions on the right hip of many years duration and an ulcerated swelling overlying the lateral part of the lesion, of 6 months duration. A skin examination showed a non-tender, welldefined pigmented brown lesion $6 \mathrm{~cm}$ in size, consisting of a flat area (Figure $1 \mathrm{~b}$ ) and an erythematous nodule of $1,5 \mathrm{~cm}$ eroded at the center, spontaneous bleeding localized at the right hip (Figure 1a). Dermoscopically, the flat area of the lesion showed a cerebriform appearance and a zone with dotted and glomerular vessels and brown to black globules, some with scales annularly

Submitted: 29 October 2019 | Accepted: 15 November 2019 | Published: 16 November 2019

${ }^{*}$ Corresponding author: Elharrouni Alaoui Aicha, Department of Dermatology, CHU Hassan II, FES, Morocco, Email: ealaouiaicha@gmail. com

Copyright: (C) 2019 Aicha EA, et al. This is an open-access article distributed under the terms of the Creative Commons Attribution License, which permits unrestricted use, distribution, and reproduction in any medium, provided the original author and source are credited.

Citation: Elharrouni Alaoui A, Douhi Z, Elloudi S, Baybay H, Mernissi Fz (2019) Eccrine Porocarcinoma: A Rare Entity and Review of the Literature. SM Dermatol J 5: 3. doi: https://dx.doi.org/10.36876/smdj646731 surrounding them (Figure 1d) and The nodule displayed scattered glomerular and hairpin vessels, with a white to pink halo and round-to-oval pink-white structureless areas, as well as haemorrhage crusts and white rail lines (Figure 1c). Due to the polymorphous vascular pattern an amelanotic melanoma or a malignant epithelial skin tumor have to be excluded. Incision biopsy from the lesion showed a pigmented APC arising from a pigmented HAS. The Computed tomography scan discovered inguinal lymph nodes metastatics. We did a wide excision of the neoplasm with negative margins. 2 months after the surgery, we combined radiotherapy-chemotherapy with cisplatin $(80 \mathrm{mg} /$ $\mathrm{m}^{2} /$ day $\times 2$ days) and 5 fluorouracil $1000 \mathrm{mg} / \mathrm{m}^{2}$ in divided doses on 2 days). Chemotherapy is started considering the risk for recurrence and metastasis. He progressed with increase in size and number of lung lesions. He has been undergoing second line chemotherapy Gemcitabin $1000 \mathrm{mg} / \mathrm{m}^{2}$.

\section{Discussion}

EPC is a rare malignant sweat gland neoplasm affecting most often people in the 6th-7th decades of life [3], with a preference for females. The tumours which occur in most cases on the trunk,

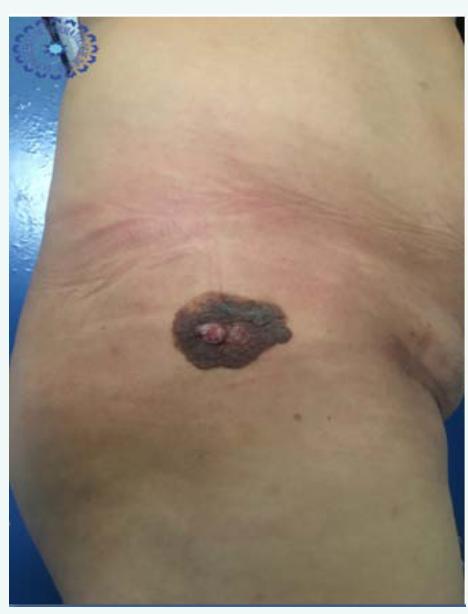

Figure 1a Clinical and dermoscopy presentations of relapsing eccrine porocarcinoma. 


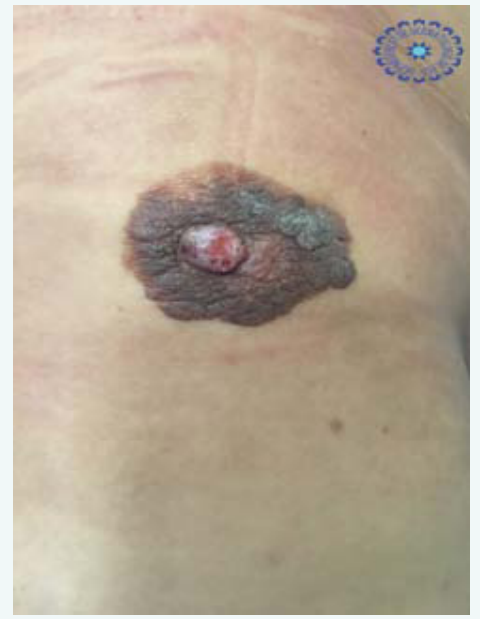

Figure $1 \mathrm{~b}$ Clinical and dermoscopy presentations of relapsing eccrine porocarcinoma.

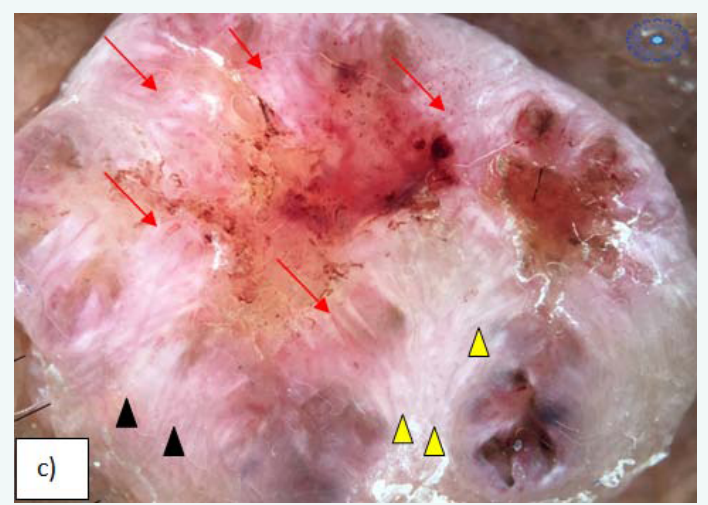

Figure 1c The papulonodules in the neoplasm dermoscopically displayed polymorphous vascular patterns including dotted, hairpin, linear irregular, and glomerular vessels with a white to pink halo (red arrows), round-to-oval pink-white structureless areas (black arrowheards) and white rail lines (yellow arrowheards).

head, neck or lower extremities [4] often show a long standing history and develop quite slowly over years, some of them following a preexisting benign eccrine poroma [5]. Its variable presentation makes it difficult to diagnose. It can appear as solitary plaque or nodular lesion, with ulcerated or hemorrhagic surface [6].

The differential diagnosis includes basal and squamous cell carcinoma, pyogenic granuloma, verruca vulgaris, adenocarcinoma, and amelanotic, pigmented, or desmoplastic nodular variants of melanoma [7].

Dermoscopy is an invaluable technique in diagnosing skin tumors. However, few cases of EPC have been reported using dermoscopic images, and their details were not well examined. Therefore, dermoscopy can provide valuable, to objectify the different dermoscopic patterns characterized by a polymorphous vascular patterns including dotted, hairpin, linear irregular, and glomerular vessels, with a white to pink halo and round-to oval pink white structureless areas, as the case of our patient [8]. Moreover, because similar structures have been described in EPC the authors' findings are concordant with previous reports suggesting that dermoscopic features may not allow for an accurate differentiation between benign and malignant tumors, and highlighting the importance of histopathologic examination for an accurate diagnosis $[9,10]$.

Usually the classic histological description of eccrine porocarcinoma is an acanthotic epithelial proliferation that contained clear cell nests with radial extension of polygonal nuclei, eosinophilic cytoplasm, and rudimentary ductal structures with many intraepidermal atypia. The diagnosis is based on morphology and is confirmed on immunohistochemistry withs glandular markes (ACE, EMA, a-lactalbumin) [11,12]. EPC is potentially fatal, it shows a high potential for a lymphatic invasion and epidermotropic metastases can also be found [13], usually they occurs in about $20 \%$ of cases with a very poor outlook and high mortality. They occurred preferentially in lymph nodes and visceral [14].

The treatment of choice in all the cases is wide excision of the lesion with histologically clear margins, however, the size of the margins has not been clearly elucidated. Alternatively, Moh's micrographic surgery has proved to be a more effective modality of treatment for eccrine porocarcinomas in diffuclt location. Furthermore, the benefits of chemotherapy and radiation therapy have not been adequately defined but with high risk of local recurrence in the metastatic eccrine porocarcinoma [1517].

\section{Conclusion}

Porocarcinoma is a very rare entity and poorly understood with morphological particularities and similarities to other carcinomas, its diagnosis is challenging. Our case is particular,

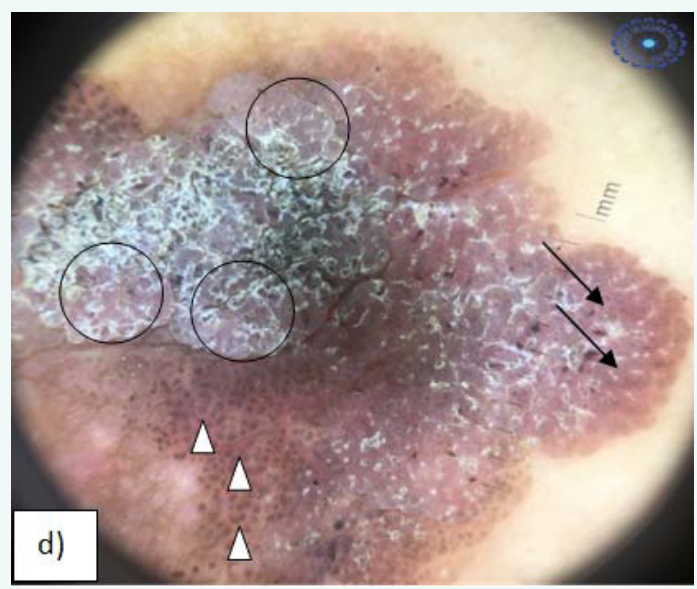

Figure 1d A brown plaque with papulonodules was seen on the patient's left thig The flat area(d) of the neoplasm dermoscopically showed a zone with cerebriform appearance (cericle) and a zone with dotted and glomerular vessels (black arrows) and brown to black globules (white arrowheards), some with scales annularly surrounding them. 
highlights not only the aggressive behavior of EPC but also the novel dermoscopy features, may represent an additional dermoscopic clue for the diagnosis of EPC.

\section{References}

1. Berke A, Grant-Kels JM. Eccrine sweat gland disorders: part I neoplasms. Int J Dermatol. 1994; 33: 79-85.

2. Argenziano G, Soyer HP, Chimenti S, Talamani R, Corona R, Sera F, et al. Dermoscopy of Pigmented Skin Lesions. An Atlas Based on the Consensus Net Meeting on Dermoscopy 2000. Milan: EDRA Medical Publishing and New Media, 2001.

3. Cazeaua C, Lepreuxb S, Taieba A, Delaunaya M, Jouarya T. Le porocarcinome eccrine: une tumeur annexielle cutanee maligne hautement aggressive. Ann Dermatol Venereol. 2008; 135: 722-724.

4. Chang NC, Tsai KB. Eccrine porocarcinoma of the auricle: a case report. Kaohsiung J Med Sci. 2009; 25: 401-404.

5. Sawaya JL, Khachemoune A. Poroma: a review of eccrine, apocrine and malignant forms. Int J Dermatol. 2014; 53: 1053-1061.

6. Robson A, Greene J, Ansari N, Kim B, Seed PT, McKee PH, et al. Eccrine porocarcinoma (malignant eccrine poroma): A clinicopathologic study of 69 cases. Am J Surg Pathol. 2001; 25: 710-720.

7. Johr R, Saghari S, Nouri K. Eccrine porocarcinoma arising in a seborrheic keratosis evaluated with dermoscopy and treated with Mohs' technique. Int J Dermatol. 2003; 42: 653-657.

8. Edamitsu T, Minagawa A, Koga H, Uhara H, Okuyama R. Eccrine porocarcinoma shares dermoscopic characteristics with eccrine poroma: a report of three cases and review of the published work. J Dermatol. 2016; 43: 332-325.

9. Kreusch JF. Vascular patterns in skin tumors. Clin Dermatol. 2002; 20: 248-254.

10. Johr R, Saghari S, Nouri K. Eccrine porocarcinoma arising in a seborrheic keratosis evaluated with dermoscopy and treated with Mohs' technique. Int J Dermatol. 2003; 42: 653-657.

11. Permali S, Chemall N, Dhotel R, Palangie A, Christoforovl B. Metastases pulmonaires $\mathrm{r}^{\prime}$ ev'elatrices d'une tumeur cutan'ee rare: le porocarcinome eccrine," La Revue de M'edecine Interne. 2000; 21: 91-94.

12. Poiares Baptiste A, Tellechea O, Reis JP. Porocarcinome eccrine: revue de 24 cas. Ann Dermatol Venereol. 1993; 120: 107-115.

13. Kim JW, Oh DJ, Kang MS, Lee D, Hwang SW, Park SW. A case of metastatic eccrine porocarcinoma. Acta Derm Venereol. 2007; 87: 550-552.

14. Snow SN, Reizner GT. Eccrine porocarcinoma of the face. J Am Acad Dermatol. 1992; 27: 306-311.

15. Yeon Ju Hong, Ji Eun Oh, You won Choi, Ki Bum Myung, Hae Young Choi. A case of cell Eccrine Porocarcinoma. Ann Dermatol. 2010; 22: 330-332.

16. Shiohara J, Koga H, Uhara H, Takata M, Saida T. Eccrine porocarcinoma: Clinical and pathological studies of 12 cases. J Dermatol. 2007; 34: 516-522.

17. Swanson JD Jr, Pazdur R, Sykes E. Metastatic sweat gland carcinoma: Response to 5-fluorouracil infusion. J Surg Oncol. 1989; 42: 69-72. 